\title{
The in vitro investigation of lycopene effects on post-thawed ram sperm
}

\author{
H.M. Souza, L.C.P. Arruda, M.M. Monteiro, I.H.A.V. Nery, R.A.J. Araújo Silva, A.S. Oliveira, \\ A.M. Batista \& M.M.P. Guerra\# \\ Andrology Laboratory, Veterinary Medicine Department, Universidade Federal Rural de Pernambuco (UFRPE), Recife, \\ 52171-900, Pernambuco, Brazil
}

(Received 3 November 2018; Accepted 26 July 2019; First published online 16 October 2019)

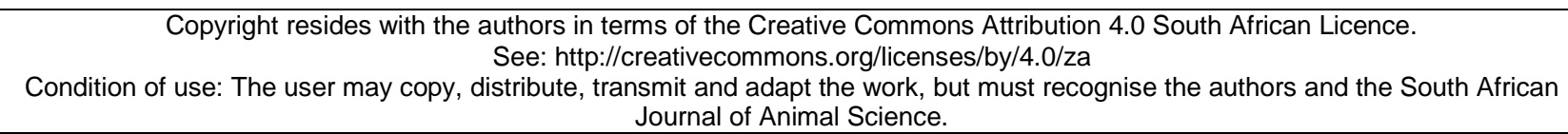
Journal of Animal Science.

\begin{abstract}
This study was conducted to evaluate the effects of lycopene on quality parameters of cryopreserved ram semen. Semen samples were collected from three Santa Inês rams to form a seminal pool $(n=8)$. Aliquots from each pool were diluted in Tris-egg yolk extender to create experimental groups containing 0 $\mu \mathrm{M}$ (control), $0.1 \mu \mathrm{M}, 1 \mu \mathrm{M}$ and $5 \mu \mathrm{M}$ lycopene. The samples were evaluated for sperm kinetics, integrity of plasma and acrosomal membranes, intracellular reactive oxygen species (ROS) production and lipid peroxidation immediately after thawing and after incubation for two hours at $37^{\circ} \mathrm{C}$. The addition of lycopene had no effect on the parameters that were evaluated at the time of thawing when compared with the control. However, after incubation, the groups with added lycopene showed a decrease in progressive motility. All experimental groups showed a significant reduction in linearity and straightness following incubation. Furthermore, the $5 \mu \mathrm{M}$ lycopene group showed a decrease in wobble and an increase in amplitude of lateral head displacement. In conclusion, the addition of lycopene to the freezing extender of ram semen affected the kinetics parameters of cryopreserved spermatozoa after a two-hour incubation period.
\end{abstract}

Keywords: carotenoid, flow cytometry, kinetic, sheep

\#Corresponding author: mmpguerra@pq.cnpq.br / mmpguerra@gmail.com

\section{Introduction}

Semen cryopreservation that is coupled with artificial insemination is a technology that has been widely used by the animal breeding industry (Sieme et al., 2015). However, despite the benefits associated with this technique, the protocols applied during freezing and thawing still affect the structure and resistance of spermatozoa (Yeste, 2016). The damage caused by cryopreservation is related to changes in the composition of the plasma membrane, to osmotic shock (Agarwal et al., 2014), and to oxidative stress that was suffered by the sperm, which led to a decline in motility and semen fertilization capacity (Gharagozloo et al., 2016). Freezing and thawing processes can increase the production of reactive oxygen species (ROS) and affect the antioxidant activity of the enzymes in seminal plasma, which is part of the oxidative control system, and can lead to an imbalance between the production of ROS and their elimination (He et al., 2016; Aly et al., 2012).

Many authors have reported the use of antioxidants in semen extenders during cryopreservation as a strategy to combat oxidative stress. The main benefits that are proposed to improve the quality of semen post thawing include a reduction in damage to the plasma and acrosomal membranes, and reduction in ROS levels and lipid peroxidation (Sangeeta et al., 2015; Amidi et al., 2016).

However, some studies have shown that there are no differences between semen samples with antioxidants and those without (Santini et al., 2014). Thus, the benefits of antioxidant therapy in sperm cryopreservation are influenced by the experimental model, the composition of the freezing medium, and the type and concentration of antioxidant (Tuncer et al., 2014).

Carotenoids such as beta-carotene and lycopene play an important role in antioxidant defence, protecting the plasma membrane against lipid peroxidation (Tuncer et al., 2014). The antioxidant effect of lycopene has been demonstrated in diabetic rats, in which the compound protected against diabetic progression, and prevented further complications, because of its capacity to refine oxidative stress and 
inflammation, and improve the systemic antioxidative capacity (Zheng et al., 2019). In addition, recent studies have presented encouraging data about the use of lycopene in freezing extenders for bovine semen (Tuncer et al., 2014; Bucak et al., 2015) and turkey semen (Rosato et al., 2012a), including the preservation of motility, acrosome and DNA integrity, and a reduction in sperm lipid peroxidation. However, there are few reports on the use of lycopene in the cryopreservation of ram semen (Uysal \& Bucak, 2007).

Therefore, this study aimed to evaluate the effects of Tris-egg yolk extender supplemented with lycopene on sperm kinetics, the integrity of plasma and acrosomal membranes, intracellular ROS production and lipid peroxidation of the plasma membrane in ram sperm after the process of freezing and thawing.

\section{Materials and Methods}

The experiments that involved animals were conducted after approval by the Ethics Committee for Animal Experimentation of the Universidade Federal Rural de Pernambuco (UFRPE), Brazil, under licence number 046/2015 CEUA/UFRPE.

The animals were maintained at the Department of Veterinary Medicine UFRPE, Pernambuco $\left(08^{\circ} 03^{\prime}\right.$ $14^{\prime \prime}$ S, $34^{\circ} 52^{\prime} 52^{\prime \prime}$ W). Three Santa Inês rams, aged two to three years, with a known history of fertility, were used in the study. All received Tifton hay, a concentrated commercial feed (400 g/animal/day), water and mineral supplementation ad libitum.

The ejaculates were obtained with the artificial vagina method, using a female as a dummy. Eight semen samples were collected per animal at 48 -hour intervals for a total of 24 ejaculates. Immediately after collection, the mass movement and motility of all semen samples were evaluated subjectively with an optical phase contrast microscope (Olympus $100 \mathrm{X}$, Tokyo, Japan). Only ejaculates with mass motion values $\geq 3$ and motility values $\geq 70 \%$ were used for pool formation $(n=8)$.

The sperm concentration was determined after pool formation using a Neubauer chamber. Sperm morphology was then evaluated with the moist chamber method (Mies Filho, 1987). The pools were approved if they presented sperm concentrations of $\geq 1 \times 10^{9} / \mathrm{mL}$ and sperm pathologies of $\leq 20 \%$.

For cryopreservation, each semen pool was diluted with Tris-egg yolk extender ( $375 \mathrm{mM}$ Tris, $124 \mathrm{mM}$ citric acid, $41.6 \mathrm{mM}$ fructose, $20 \%$ egg yolk, $5 \%$ glycerol, $\mathrm{pH} 6.8$ ) to a final concentration of $200 \times 10^{6}$ spermatozoa/mL. After dilution, the sample was divided to form these experimental groups with the addition of lycopene: 0 (control), $0.1 \mu \mathrm{M}, 1 \mu \mathrm{M}$, and $5 \mu \mathrm{M}$. The final DMSO concentration in all groups was $0.05 \%$.

After packaging in labelled $0.25 \mathrm{~mL}$ straws, the samples were frozen with an automated system (TK Tecnologia em Congelação Ltd., Uberaba, Brazil). A refrigeration curve of $-0.25{ }^{\circ} \mathrm{C} / \mathrm{min}$ was used, beginning at room temperature $\left(27^{\circ} \mathrm{C}\right)$. After it reached $5^{\circ} \mathrm{C}$, the semen was subjected to a stabilization period for 120 min. After stabilization, a freezing curve of $-15{ }^{\circ} \mathrm{C} / \mathrm{min}$ was initiated until $-120^{\circ} \mathrm{C}$ was reached. The straws were then stored in liquid nitrogen $\left(-196^{\circ} \mathrm{C}\right)$ until analysis.

The experimental groups were evaluated at two points, namely immediately after thawing, and after two-hour incubation at $37^{\circ} \mathrm{C}$. Two straws of semen from each experimental group were thawed $\left(37^{\circ} \mathrm{C} / 30 \mathrm{~s}\right)$ and paired. Eight replicates were performed for all experimental groups.

The sperm kinetics were evaluated using a computerized system for sperm analysis (CASA, SCA ${ }^{\mathrm{TM}}$ Microptics, SL, Version 5.1, Barcelona, Spain). A $10 \mu \mathrm{L}$ semen aliquot was diluted with Tris-egg yolk extender without glycerol (375 mM Tris, $124 \mathrm{mM}$ citric acid, $41.6 \mathrm{mM}$ fructose, $20 \%$ egg yolk, $\mathrm{pH} 6.8$ ) and preheated to $37^{\circ} \mathrm{C}$ to achieve a concentration of $50 \times 10^{6}$ spermatozoa $/ \mathrm{mL}$.

For analysis, an aliquot of the sample $(2.5 \mu \mathrm{L})$ was placed on a slide and covered with cover slip (18 $\mathrm{x}$ $18 \mathrm{~mm}$ ). Both were preheated at $37^{\circ} \mathrm{C}$ and evaluated via phase contrast microscopy (Eclipse 50i, Nikon, Japan). A video camera (Basler Vision Tecnologie ${ }^{T M}$ A312FC, Ahrensburg, Germany) at 100x magnification was used to capture images of sperm cells. Five random and non-consecutive fields were recorded for each sample, and at least 500 sperm cells were recorded.

These sperm kinetic variables were assessed: total motility (TM) (\%), progressive motility (PM) (\%), curvilinear velocity $(\mathrm{VCL})(\mu \mathrm{m} / \mathrm{s})$, straight-line velocity $(\mathrm{VSL})(\mu \mathrm{m} / \mathrm{s})$, average path velocity (VAP) $(\mu \mathrm{m} / \mathrm{s})$, linearity (LIN) (\%), straightness (STR) (\%), wobble (WOB) (\%), amplitude of lateral head displacement (ALH) $(\mu \mathrm{m})$, and beat-cross frequency $(\mathrm{BCF})(\mathrm{Hz})$. The CASA system variables were measured using these settings: temperature $\left(37^{\circ} \mathrm{C}\right)$, magnification $(100 \mathrm{x})$, frames per second $(25)$, area of the head $\left(20-70 \mu \mathrm{m}^{2}\right)$, $\operatorname{VAP}$ (slow $10 \mu \mathrm{m} / \mathrm{s}$, medium $45 \mu \mathrm{m} / \mathrm{s}$, rapid $75 \mu \mathrm{m} / \mathrm{s}$ ), progressiveness (80\% STR) and circularity (50\% LIN).

All reagents used in this study were purchased from Sigma-Aldrich (St. Louis, MO, USA), unless noted otherwise. A stock solution of $1 \mathrm{mg} / \mathrm{mL}$ was obtained from the dilution $1 \mathrm{mg}$ lycopene (L9879) in $1 \mathrm{~mL}$ dimethyl sulfoxide (DMSO) solvent that was heated to $37^{\circ} \mathrm{C}$ and then stored at $-80{ }^{\circ} \mathrm{C}$. These procedures were performed for all cytometry assays, namely integrity of the plasma and acrosomal membranes (iPAM), intracellular ROS production and lipid peroxidation of the plasma membrane. Forty-microlitre aliquots of semen $\left(200 \times 10^{6}\right.$ spermatozoa/mL) were diluted in $1 \mathrm{~mL}$ PBS (Dulbecco's phosphate-buffered saline, Ca2+ 
and $\mathrm{Mg} 2+$ free) and centrifuged $(600 \times \mathrm{g} / 10 \mathrm{~min})$ to remove the extender and cellular debris. The supernatant was then discarded, and the sperm pellet was re-suspended in $40 \mu \mathrm{L}$ PBS.

For iPAM evaluation, the samples were stained with $1.0 \mu \mathrm{L}$ fluorescein isothiocyanate-peanut agglutinin (FITC-PNA) $(200 \mu \mathrm{g} / \mathrm{mL}$ in PBS) and $2.0 \mu \mathrm{L}$ propidium iodide (PI) $(0.5 \mathrm{mg} / \mathrm{mL}$ in PBS), fixed with $5.0 \mu \mathrm{L} 4 \%$ paraformaldehyde, and incubated for $10 \mathrm{~min}$ at room temperature.

For the evaluation of lipid peroxidation, the cells were stained with $1.0 \mu \mathrm{L}$ C11-BODIPY ${ }^{581 / 591}(2 \mathrm{mM}$ in DMSO) (Molecular Probes, Life Technologies, Eugene, USA). To evaluate intracellular ROS production, 2.0 $\mu \mathrm{L} \mathrm{CM}-\mathrm{H}_{2}$ DCFDA (0.5 mM in DMSO) (Molecular Probes, Life Technologies, Eugene, USA) were added. For both analyses, the samples were incubated at $37^{\circ} \mathrm{C}$ for $30 \mathrm{~min}$. Excess probe was removed by diluting the samples with $1 \mathrm{~mL}$ PBS and centrifuging $(600 \times \mathrm{g} / 10 \mathrm{~min})$. The pellets were re-suspended in $40 \mu \mathrm{L}$ PBS, fixed with $5.0 \mu \mathrm{L} 4 \%$ paraformaldehyde, incubated for $10 \mathrm{~min}$ at room temperature and evaluated. Similarly to the analysis of intracellular ROS production, $1.0 \mu \mathrm{L} \mathrm{PI}(0.5 \mathrm{mg} / \mathrm{mL}$ in PBS) was added before the cells were fixed.

An Amnis ImageStream Mark II flow cytometer (EMD Millipore Corp., Seattle, USA) that was equipped with a $60 \mathrm{x}$ microscope objective $(0.5 \mu \mathrm{m}$ pixel resolution) with an image rate of $5000 \mathrm{cells} / \mathrm{s}$ was used for cytometric analysis. The cell size was $7.0 \mathrm{~m}$ and the flow velocity was $44 \mathrm{~mm} / \mathrm{s}$. The analyses were performed with a $488 \mathrm{~nm}$ laser with intensity settings of $55.0 \mathrm{~mW}$ (iPAM analysis), $60.0 \mathrm{~mW}$ (lipid peroxidation), and $80.0 \mathrm{~mW}$ (ROS production). A total of 5000 events were collected for all samples. Brightfield imagery was collected with an LED-based brightfield illuminator (channel 1); FITC-PNA and CMH2DCFDA were collected on channel 2 (505-560 nm); IP on channel 5 (640-745 nm); and C11BODIPY ${ }^{581 / 591}$ on channels 2 and $4(595-640 \mathrm{~nm})$. INSPIRE ${ }^{\circledR}$ software was used to acquire raw images, and IDEAS $^{\circledR}$ software version 6.0 was used to analyse these images.

In the iPAM evaluation, cells were classified as cells with intact acrosomal and plasma membranes (unstained); cells with damaged acrosomal membranes and intact plasma membranes (stained only by FITC-PNA); cells with intact acrosomal membranes and damaged plasma membranes (stained only IP); and cells with damaged acrosomal and plasma membranes (double stained). In the analysis of intracellular ROS production, cells were classified as cells with low ROS levels and intact plasma membranes (not stained); cells with high levels of ROS and intact plasma membrane (marked only by $\mathrm{CM}-\mathrm{H}_{2} \mathrm{DCFDA}$ ); and cells with damaged plasma membranes (stained only IP). For lipid peroxidation, cell membranes stained orange did not show peroxidation, and cells stained green showed peroxidation.

All results are expressed as the means \pm standard deviation. The arcsine method (arcsine $\sqrt{ } \mathrm{P} / 100)$ was used to transform all variables into percentages. Kolmogorov-Smirnov and Bartlett's tests were used to test the data for residual normality and homogeneity of variance, respectively. The data were log or square root transformed to obtain a normal distribution when necessary. Finally, all data were analysed using an analysis of variance (ANOVA) and a Tukey's test with a significance level of $5 \%(P<0.05)$. GraphPad InStat 3.0 software was used for data processing.

\section{Results}

Table 1 presents the data from the sperm kinetic analysis (CASA) of fresh semen and frozen-thawed semen supplemented with various concentrations of lycopene.

The values of TM, PM, VSL, VAP and WOB were higher $(P<0.05)$ in samples of fresh semen than in the treatment groups (control, $0.1 \mu \mathrm{M}, 1 \mu \mathrm{M}$ and $5 \mu \mathrm{M}$ lycopene) after cryopreservation. LIN was higher $(P$ $<0.05)$ in samples of fresh semen than in samples subjected to freezing/thawing with $0 \mu \mathrm{M}, 0.1 \mu \mathrm{M}$ and $1 \mu \mathrm{M}$ of lycopene, but did not differ $(P>0.05)$ from the $5 \mu \mathrm{M}$ group. BCF was lower $(P<0.05)$ in samples of fresh semen compared with cryopreserved samples. There were no differences $(P>0.05)$ between samples of fresh semen and frozen/thawed semen for VCL, STR and ALH.

For all kinetic variables assessed, no difference $(P>0.05)$ was found between the control group and the groups supplemented with lycopene, both after thawing $(0 \mathrm{~h})$ and after the incubation period $(2 \mathrm{~h})$. However, within the same treatment group, the authors observed differences in some kinetic variables before and after incubation. The groups treated with $0.1,1$ and $5 \mu \mathrm{M}$ lycopene showed a decrease $(P<0.05)$ in PM, LIN and STR after $2 \mathrm{~h}$ of incubation. Furthermore, the group with $5 \mu \mathrm{M}$ lycopene showed a decrease in WOB and an increase in ALH $(P<0.05)$. The control group, after $2 \mathrm{~h}$ of incubation, showed a decrease in LIN and STR and an increase in BCF $(P<0.05)$. 
Table 1 Sperm kinetics variables (mean \pm SD) of fresh and cryopreserved ram semen with and without the addition of lycopene post thawing $(0 \mathrm{~h})$ and after incubation for two hours at $37^{\circ} \mathrm{C}$

\begin{tabular}{|c|c|c|c|c|c|c|c|c|c|c|c|}
\hline Time & Treatment & TM (\%) & PM (\%) & VCL $(\mu \mathrm{m} / \mathrm{s})$ & VSL $(\mu \mathrm{m} / \mathrm{s})$ & $\operatorname{VAP}(\mu \mathrm{m} / \mathrm{s})$ & LIN (\%) & STR (\%) & WOB (\%) & $\mathrm{ALH}(\mu \mathrm{m})$ & $\mathrm{BCF}(\mathrm{Hz})$ \\
\hline \multicolumn{2}{|c|}{ Fresh semen } & $87.6^{a} \pm 2.4$ & $67.0^{a} \pm 6.1$ & $91.0 \pm 12.8$ & $73.5^{a} \pm 14.1$ & $81.1^{a} \pm 14.0$ & $80.5^{\mathrm{a}} \pm 8.5$ & $90.2 \pm 3.6$ & $89.0^{a} \pm 6.5$ & $1.9 \pm 0.4$ & $9.0^{\mathrm{b}} \pm 1.2$ \\
\hline \multirow{4}{*}{$\mathrm{Oh}$} & Control & $60.6^{b} \pm 6.2$ & $37.6^{b} \pm 9.3$ & $85.2 \pm 7.0$ & $54.3^{\mathrm{b}} \pm 8.6$ & $64.5^{b} \pm 7.1$ & $63.9^{\mathrm{b} . \mathrm{A}} \pm 9.8$ & $83.9^{A} \pm 5.6$ & $75.8^{b} \pm 6.7$ & $2.4 \pm 0.4$ & $12.1^{\mathrm{a} . \mathrm{B}} \pm 1.4$ \\
\hline & $0.1 \mu \mathrm{M}$ & $56.0^{b} \pm 7.8$ & $37.4^{\mathrm{b} . \mathrm{A}} \pm 8.4$ & $88.3 \pm 8.8$ & $56.2^{\mathrm{b}} \pm 7.1$ & $66.3^{b} \pm 6.4$ & $64.1^{\text {b.A }} \pm 9.0$ & $84.7^{A} \pm 5.4$ & $75.3^{b} \pm 6.1$ & $2.4 \pm 0.3$ & $12.6^{\mathrm{a}} \pm 0.9$ \\
\hline & $1 \mu \mathrm{M}$ & $65.8^{b} \pm 6.1$ & $40.0^{\mathrm{b} . \mathrm{A}} \pm 6.0$ & $88.1 \pm 9.7$ & $55.9^{b} \pm 6.2$ & $66.6^{\mathrm{b}} \pm 6.4$ & $64.0^{\mathrm{b} . \mathrm{A}} \pm 7.8$ & $84.1^{A} \pm 6.3$ & $75.8^{b} \pm 4.2$ & $2.4 \pm 0.3$ & $12.5^{\mathrm{a}} \pm 0.9$ \\
\hline & $5 \mu \mathrm{M}$ & $56.6^{b} \pm 16.3$ & $36.8^{\mathrm{b} . \mathrm{A}} \pm 14.9$ & $82.6 \pm 6.8$ & $56.6^{b} \pm 11.3$ & $65.7^{b} \pm 9.1$ & $68.5^{\mathrm{ab} . \mathrm{A}} \pm 12.0$ & $85.7^{\mathrm{A}} \pm 6.9$ & $79.5^{\mathrm{b} . \mathrm{A}} \pm 7.9$ & $2.1^{B} \pm 0.3$ & $11.9^{\mathrm{a}} \pm 1.1$ \\
\hline \multirow{4}{*}{$2 \mathrm{~h}$} & Control & $62.6 \pm 10.4$ & $24.3 \pm 7.1$ & $97.8 \pm 9.5$ & $45.9 \pm 6.3$ & $66.2 \pm 7.4$ & $47.0^{B} \pm 5.0$ & $69.3^{\mathrm{B}} \pm 5.5$ & $67.7 \pm 2.1$ & $2.9 \pm 0.2$ & $13.7^{\mathrm{A}} \pm 0.5$ \\
\hline & $0.1 \mu \mathrm{M}$ & $58.6 \pm 10.5$ & $19.7^{\mathrm{B}} \pm 7.0$ & $100.9 \pm 10.0$ & $45.8 \pm 4.9$ & $69.5 \pm 8.4$ & $45.6^{\mathrm{B}} \pm 5.7$ & $66.3^{\mathrm{B}} \pm 6.5$ & $68.8 \pm 3.5$ & $2.9 \pm 0.2$ & $13.0 \pm 0.8$ \\
\hline & $1 \mu \mathrm{M}$ & $63.1 \pm 10.0$ & $22.9^{B} \pm 8.3$ & $99.8 \pm 7.3$ & $46.9 \pm 7.4$ & $68.1 \pm 5.7$ & $47.3^{B} \pm 8.6$ & $68.7^{B} \pm 8.5$ & $68.3 \pm 4.5$ & $3.0 \pm 0.2$ & $13.2 \pm 0.5$ \\
\hline & $5 \mu \mathrm{M}$ & $60.1 \pm 17.5$ & $19.8^{B} \pm 5.8$ & $96.2 \pm 9.1$ & $45.2 \pm 6.2$ & $65.6 \pm 7.7$ & $47.2^{\mathrm{B}} \pm 5.9$ & $69.1^{B} \pm 6.6$ & $68.1^{B} \pm 3.0$ & $2.9^{\mathrm{A}} \pm 0.2$ & $13.2 \pm 0.5$ \\
\hline
\end{tabular}

$\overline{a, b}$ Row means with different superscripts differ significantly at $P<0.05$ among treatments at $0 \mathrm{~h}$ and for fresh semen

$A, B$ Row means with different superscripts differ significantly $P<0.05$ among time periods within the same treatment

TM: total motility; PM: progressive motility; VCL: curvilinear velocity; VSL: straight-line velocity; VAP: average path velocity; LIN: linearity; STR: straightness; WOB: wobble;

ALH: amplitude of lateral head displacement; BCF: beat-cross frequency 
The data from the flow cytometry analysis of fresh semen and cryopreserved semen supplemented with various concentrations of lycopene are presented in Table 2. Fresh semen samples showed greater $(P$ $<0.05)$ integrity of the plasma and acrosomal membranes compared with the treatment groups after cryopreservation. There were no differences $(P>0.05)$ in intracellular ROS production and lipid peroxidation of the plasma membrane between samples of fresh semen and groups treated with lycopene, after freezing/thawing.

Table 2 Integrity of the plasma and acrosomal membranes, intracellular oxygen reactive species production and lipid peroxidation of the plasma membrane (mean \pm SD) of fresh and cryopreserved ram semen with and without lycopene post thawing $(\mathrm{O} \mathrm{h})$ and after incubation for two hours at $37^{\circ} \mathrm{C}$

\begin{tabular}{llccc}
\hline Time & Treatment & PNA-/PI- (\%) & DCFDA- (\%) & C11- (\%) \\
\hline \multirow{4}{*}{$0 \mathrm{~h}$} & Fresh semen & $85.9^{\mathrm{a}} \pm 3.2$ & $80.8 \pm 18.9$ & $99.0 \pm 0.6$ \\
\hline & Control & $32.8^{\mathrm{b}} \pm 4.3$ & $66.5 \pm 13.8$ & $97.9 \pm 0.7$ \\
& $0.1 \mu \mathrm{M}$ & $30.4^{\mathrm{b}} \pm 6.3$ & $69.0 \pm 11.4$ & $98.1 \pm 0.6$ \\
& $1 \mu \mathrm{M}$ & $32.1^{\mathrm{b}} \pm 6.7$ & $69.1 \pm 19.1$ & $98.3 \pm 0.6$ \\
& $5 \mu \mathrm{M}$ & $27.6^{\mathrm{b}} \pm 5.3$ & $74.1 \pm 8.7$ & $98.4 \pm 0.7$ \\
\hline \multirow{3}{*}{$\mathrm{h}$} & Control & $40.1 \pm 4.2$ & $80.5 \pm 9.2$ & $97.2 \pm 2.1$ \\
& $0.1 \mu \mathrm{M}$ & $35.8 \pm 4.5$ & $83.5 \pm 6.1$ & $97.3 \pm 2.3$ \\
& $1 \mu \mathrm{M}$ & $35.7 \pm 4.0$ & $83.5 \pm 5.5$ & $97.5 \pm 1.6$ \\
& $5 \mu \mathrm{M}$ & $32.2 \pm 6.4$ & $79.1 \pm 11.5$ & $97.7 \pm 1.4$
\end{tabular}

\footnotetext{
${ }^{a, b}$ Row means with different superscripts differ significantly at $P<0.05$ among treatments at $0 \mathrm{~h}$ and for fresh semen PNA-/PI-: cells with intact plasma and acrosomal membranes (FITC-PNA + PI); DCFDA-: cells with low intracellular oxygen reactive species levels and intact plasma membrane $\left(C M-\mathrm{H}_{2} \mathrm{DCFDA}+\mathrm{PI}\right)$; only intact cells were included in the calculation of this variable; C11-: cells without lipid peroxidation in the plasma membrane (C11-BODIPY ${ }^{591581}$ )
}

There were no differences $(P>0.05)$ among the treatment groups within each period $(0 \mathrm{~h}$ and $2 \mathrm{~h})$ and between times for each treatment group in the integrity of plasma and acrosomal membranes, intracellular ROS production and lipid peroxidation of the plasma membrane.

\section{Discussion}

Long-term sperm storage (cryopreservation and cold shock) results in a decrease in sperm motility and in the integrity of plasma and acrosomal membranes owing to modifications in highly specialized regions of the sperm plasma membrane, leading to alterations of sperm functions (Tvrdá et al., 2016). Many studies have reported a decrease in sperm motility and the occurrence of lesions in the plasma membrane after cryopreservation. These phenomena represent a major source of damage to cryopreserved sperm (Pelufo et al., 2015).

This experiment showed no statistically significant differences in kinetic variables and the integrity of plasma and acrosomal membranes between the control group and lycopene-supplemented groups after thawing. These data corroborate those reported by Rosato et al. (2012a) with turkey semen and Rosato et al. (2012b) with rabbit semen. These authors found no improvement in TM, PM, viability, and acrosomal integrity of semen samples supplemented with lycopene compared with a control group after thawing. Similarly, Bucak et al. (2015) found no changes in kinetic variables (VAP, VSL, VCL, ALH, and LIN), cell viability, and integrity of the acrosome after thawing samples of bovine semen supplemented with lycopene.

This study differed from that of Bucak et al. (2015), which described an increase in TM and PM of $5.1 \%$ and $4.7 \%$, respectively, in samples of post-freezing bovine semen. Similarly, Uysal \& Bucak (2007) demonstrated a protective effect of lycopene on the motility and viability of cryopreserved ram sperm. These discrepancies can be attributed to the experimental model (species) and the lycopene concentrations that were tested, which were much higher than those used in the present study. Furthermore, the techniques that were used to evaluate motility (subjective method) and plasma membrane integrity (staining with eosinnigrosin) were different from those used in this study, which could give a large margin of error of the results.

A recent study on the characteristics of ovine sperm motility showed that progressive motility is one of the most consistent indicators of fertility (Yániz et al., 2015). Thus, the effect of lycopene at concentrations of 
$0.1 \mu \mathrm{M} \mu \mathrm{M}, 1$ and $5 \mu \mathrm{M}$ on the progressive motility of sperm after incubation can influence the fertility of cryopreserved semen. In this study, after two hours of incubation, the samples that were supplemented with lycopene showed a significant decrease in PM compared with samples immediately post thaw $(0 \mathrm{~h})$, which was not observed in the control group. In this case, it can be inferred that under these conditions the addition of various concentrations of lycopene could be detrimental to some seminal characteristics.

Carotenoids interact with lipid membranes, changing their physical and dynamic properties in a concentration-dependent manner (Xia et al., 2015). Incorporation of polar carotenoids into the lipid membrane can increase the rigidity and stability of the membrane, whereas non-polar carotenoids may have the opposite effect (Gruszecki \& Strzałka, 2005; McNulty et al., 2007).

The structural location of exogenous lycopene in spermatozoa has not been studied. However, when lycopene, a non-polar carotenoid, is incorporated into the liposomes of egg yolk, it is situated deep inside the hydrophobic core of the lipid bilayer and, depending on the concentration, could increase membrane fluidity (Xia et al., 2015). Another study demonstrated that an increase in lycopene concentration caused a disturbance of the lipid bilayer, resulting in a decreased barrier against the penetration of molecular oxygen and other small molecules through the liposomal membrane (Tan et al., 2014).

In addition, lycopene has shown various biological functions, among them the regulation of enzymatic activity (Eldahshan \& Singab, 2013). This carotenoid is involved in the reduction of the activity of hydroxymethylglutaryl coenzyme A (HMG-CoA) reductase, causing an inhibition of the synthesis of melonovate, a precursor of ubiquinone (coenzyme Q10), which is a key coenzyme in the mitochondrial respiratory chain. Thus, the decrease in ubiquinone levels may lead to mitochondrial dysfunction (Pinieux et al., 1996; Nishimura et al., 2019), which would justify a reduction in the progressive motility of the lycopene-treated groups.

Exposure of Candidas albicans to lycopene may promote an overload of intracellular Ca2+ levels. Lycopene causes elevation of $\mathrm{Ca} 2+$ by damaging inflow and exportation across the plasma membrane or by releasing intracellular Ca2+ stores via the apoptotic pathway (Choi \& Lee, 2015). The increase in intracellular $\mathrm{Ca} 2+$ is related to the hyperactivation of the sperm cell, which is characterized by the reduction of progressive motility (García-Alvarez et al., 2013), which was observed in the groups treated with lycopene after incubation.

In this experiment, the evaluation of intracellular ROS production in semen samples indicated that no effect was observed of the addition of various concentrations of lycopene on oxidative stress, resulting in no differences in comparing the control with the times evaluated ( 0 and 2 hours). Carotenoids such as lycopene are important components of antioxidant defence. Studies have shown that this compound can improve sperm motility, membrane integrity and DNA damage (Zini et al., 2010). However, in this experiment it was demonstrated that under certain conditions, even after cryopreservation and thawing, the ROS levels were not increased. Thus the antioxidant function of lycopene could be analysed. Corroborating this study, Santiani et al. (2014) showed no differences in ROS levels between fresh semen and cryopreserved semen under certain conditions.

Regarding lipid peroxidation, no significant differences were observed in the treatments with lycopene compared with the control group. According to the values, more than $95 \%$ of the sperm cells were presented without lipid peroxidation in the plasma membrane.

Supplementation of semen with lycopene has produced conflicting results in vitro. In turkey semen (Rosato et al., 2012a) and rabbit semen (Rosato et al., 2012b), reductions in lipid peroxidation were observed after cryopreservation. In contrast, supplementation of bovine semen extender with lycopene resulted in an increase in lipid peroxidation (Tuncer et al., 2014). Several studies have demonstrated that the cryopreservation process of semen results an increase in lipid peroxidation and correlates with an increase in ROS levels, with a consequent decrease in semen quality (Ashrafi et al., 2013; Karimfar et al., 2015). However, other studies have demonstrated no increase in lipid peroxidation after the freezing/thawing process (Guthrie \& Welch, 2007; Peris et al., 2007), corroborating the current findings and demonstrating that lipid peroxidation might not occur under certain experimental conditions.

The current results demonstrate that the cryopreservation process did not cause an increase in oxidative stress and lipid peroxidation of the plasma membrane of cryopreserved ovine sperm, which may cause a limitation of the protective effect of lycopene on these variables. These findings have practical implications, because the use of lycopene as a semen extender additive has been recommended, and some studies have shown that its addition improves semen quality. However, the mechanism of action of lycopene on ram sperm remains to be elucidated.

\section{Conclusion}

The addition of lycopene to the Tris-egg yolk extender in ram semen cryopreservation had no effect on the integrity of plasma and acrosomal membranes, intracellular ROS production and lipid peroxidation of the 
cell membrane. However, after the incubation of semen for two hours at $37^{\circ} \mathrm{C}$, the addition of lycopene at concentrations of $0.1 \mu \mathrm{M}, 1 \mu \mathrm{M}$ and $5 \mu \mathrm{M}$ affects the progressive motility of cryopreserved spermatozoa.

\section{Acknowledgements}

The authors are grateful to the Brazilian agencies Fundação de Amparo à Ciência e Tecnologia do Estado de Pernambuco (FACEPE) and Conselho Nacional de Desenvolvimento Científico e Tecnológico (CNPq) for funding.

\section{Authors' Contributions}

HMS, AMB and MMPW designed the experiment. HMS, LCPA, MMM, IHAVN, RAJAS, ASO conducted the experiment. HMS, RAJAS and AMB analysed the data and interpreted the results.

\section{Conflict of Interest Declaration}

The authors declare that there is no conflict of interest that could be perceived as prejudicing the impartiality of the research reported.

\section{References}

Agarwal, A., Virk, G., Ong, C. \& du Plessis, S.S. ,2014. Effect of oxidative stress on male reproduction. World J. Mens. Health. 32, 1-17. Doi: 10.5534/wjmh.2014.32.1.1.

Aly, H.A.A., El-Beshbishy, H.A. \& Banjar, Z.M., 2012. Mitochondrial dysfunction induced impairment of spermatogenesis in LPS-treated rats: Modulatory role of lycopene. Eur. J. Pharmacol. 677, 31-38. Doi: 10.1016/j.ejphar.2011.12.027.

Amidi, F., Pazhohan, A., Shabani, M., Nashtaei, M. Khodarahmian, M., 2016. The role of antioxidants in sperm freezing: a review. Cell Tissue Bank. 17, 745-756. Doi: 10.1007/s10561-016-9566-5.

Ashrafi, I., Kohram, H. \& Ardabili, F.F., 2013. Antioxidative effects of melatonin on kinetics, microscopic and oxidative parameters of cryopreserved bull spermatozoa. Anim. Reprod. Sci. 139, 25-30. Doi: 10.1016/j.anireprosci.2013.03.016.

Bucak, M.N., Ataman, M.B., Başpinar, N., Uysal, O., Taşpinar, M., ..., Akal, E., 2015. Lycopene and resveratrol improve post-thaw bull sperm parameters: Sperm motility, mitochondrial activity and DNA integrity. Andrologia 47, 545552. https://doi: 10.1111/and.12301.

Choi, H. \& Lee, D.G., 2015. Lycopene induces apoptosis in Candida albicans through reactive oxygen species production and mitochondrial dysfunction. Biochimie. 115, 108-115. doi: 10.1016/j.biochi.2015.05.009.

De Pinieux, G., Chariot, P., Ammi-Saïd, M., Louarn, F., Lejonc, J.L., ..., Gherardi, R., 1996. Lipid-lowering drugs and mitochondrial function: Effects of HMG-CoA reductase inhibitors on serum ubiquinone and blood lactate/pyruvate ratio. Br. J. Clin. Pharmacol. 42, 333-337. https://doi.org/10.1046/j.1365-2125.1996.04178.x.

Eldahshan, O.A. \& Singab, A.N.B., 2013. Carotenoids. J. Pharmacogn. Phytochem. 2, 225-234.

García-Álvarez, O., Maroto-Morales, A., Ramón, M., Del Olmo, E., Jiménez-Rabadán, P., ..., Soler, A.J., 2014. Dynamics of sperm subpopulations based on motility and plasma membrane status in thawed ram spermatozoa incubated under conditions that support in vitro capacitation and fertilisation. Reprod. Fertil. Dev. 26, 725-732. doi: 10.1071/RD13034.

Gharagozloo, P., Gutiérrez-Adán, A., Champroux, A., Noblanc, A., Kocer, A., .., Aitken, R.J., 2016. A novel antioxidant formulation designed to treat male infertility associated with oxidative stress: Promising preclinical evidence from animal models. Human Reproduction 31, 252-2562. Doi: 10.1093/humrep/dev302.

Gruszecki, W.I. \& Strzałka, K., 2005. Carotenoids as modulators of lipid membrane physical properties. Biochim. Biophys. Acta 1740, 108-115. https://doi: 10.1016/j.bbadis.2004.11.015.

Guthrie, H.D. \& Welch, G.R., 2007. Use of fluorescence-activated flow cytometry to determine membrane lipid peroxidation during hypothermic liquid storage and freeze-thawing of viable boar sperm loaded with C11BODIPY $^{581 / 591}$. J. Anim. Sci. 85, 1402-1411. https:// doi: 10.2527/jas.2006-787.

He,Y.X., Wang,K., Zhao,X.X., Zhang,Y., Ma,Y.J. \& Hu, J.J., 2016 Differential proteome association study of freeze-thaw damage in ram sperm. Cryobiology 72, 60-68. http://doi: 10.1016/j.cryobiol.2015.11.003.

Hyemin, C. \& Dong G.L. 2015. Lycopene induces apoptosis in Candida albicans through reactive oxygen species production and mitochondrial dysfunction. Biochimie 115, 108-115. Doi: 10.1016/j.biochi.2015.05.009.

Karimfar, M.H., Niazvand, F., Haghani, K., Ghafourian, S., Shirazi, R. \& Bakhtiyari, S., 2015. The protective effects of melatonin against cryopreservation-induced oxidative stress in human sperm. Int. J. Immunopathol. Pharmacol. 28, 69-76. https://doi: 10.1177/0394632015572080.

McNulty, H.P., Byun, J., Lockwood, S.F., Jacob, R.F. \& Mason, R.P., 2007. Differential effects of carotenoids on lipid peroxidation due to membrane interactions: X-ray diffraction analysis. Biochi. Biophys. Acta. 1768, 167-174. https://doi: 10.1016/j.bbamem.2006.09.010.

Nishimura, M., Tominaga, N., Ishikawa-Takano, Y., Maeda-Yamamoto, M. \& Nishihira, J., 2019. Effect of 12-week daily intake of the high-lycopene tomato (Solanum lycopersicum), a variety named 'PR-7', on lipid metabolism: A randomized, double-blind, placebo-controlled, parallel-group study. Nutrients 11, 1177; doi:10.3390/nu11051177.

Pelufo, V., López Armengol, M.F., Malcotti, V., Venturino, A. \& Aisen, E.G., 2015. Effects of glycerol and sugar mixing temperature on the morphologic and functional integrity of cryopreserved ram sperm. Theriogenology 83, 144151. https://doi: 10.1016/j.theriogenology.2014.09.007. 
Peris, S.I., Bilodeau, J.F., Dufour, M. \& Bailey, J.L., 2007. Impact of cryopreservation and reactive oxygen species on DNA integrity, lipid peroxidation, and functional parameters in ram sperm. Mol. Reprod. Dev. 74: 878-892. https://doi: 10.1002/mrd.20686.

Rosato, M.P., Centoducati, G., Santacroce, M.P. \& Iaffaldano, N., 2012a. Effects of lycopene on in vitro quality and lipid peroxidation in refrigerated and cryopreserved turkey spermatozoa. British Poultry Sci. 53, 545-552. https://doi: 10.1080/00071668.2012.716508.

Rosato, M.P., Diiorio, M., Manchisi, A., Gambacorta, M., Petrosino, G., Centoducati, G., Santacroce, M.P. \& laffaldano, N., 2012b. In vitro survival and lipid peroxidation status of rabbit spermatozoa after both chilled and frozen storage in lycopene enriched extenders. Livest. Sci. 146, 199-202. https://doi: 10.1016/j.livsci.2012.03.006.

Sangeeta, S., Arangasamy, A., Kulkarni, S. \& Selvaraju, S. 2015. Role of amino acids as additives on sperm motility, plasma membrane integrity and lipid peroxidation levels at pre-freeze and post-thawed ram semen. Anim. Reprod. Sci. 161, 82-88. https://doi: 10.1016/j.anireprosci.2015.08.008.

Santiani, A., Evangelista, S., Sepúlveda, N., Risopatrón, J., Villegas, J. \& Sánchez, R., 2014. Addition of superoxide dismutase mimics during cooling process prevents oxidative stress and improves semen quality parameters in frozen/thawed ram spermatozoa. Theriogenology. 82, 884-889. https://doi: 10.1016/j.theriogenology.2014.07.002.

Sieme, H., Oldenhof, H. \& Wolkers, W.F., 2015. Sperm membrane behavior during cooling and cryopreservation. Reprod. Domest. Anim. 50, 20-26. https://doi: 10.1111/rda.12594.

Tan, C., Xue, J., Abbas, S., Feng, B., Zhang, X. \& Xia, S., 2014. Liposome as a delivery system for carotenoids: comparative antioxidant activity of carotenoids as measured by ferric reducing antioxidant power, DPPH assay and lipid peroxidation. J. Agricult. Food. Chem. 62, 6726-6735. https://doi: 10.1021/jf405622f.

Tuncer, P.B., Büyükleblebici, S., Eken, A., Taşdemir, U., Durmaz, E., Büyükleblebici, O. \& Çoşkun, E. 2014. Comparison of cryoprotective effects of lycopene and cysteamine in different cryoprotectants on bull semen and fertility results. Reprod. Domest. Anim. 49, 746-752. https://doi: 10.1111/rda.12359.

Tvrdá, E., Tušimová, E., Kováčik, A., Paál, D. \& Libová, L., 2016. Protective effects of quercetin on selected oxidative biomarkers in bovine spermatozoa subjected to ferrous ascorbate. Reprod. Domest. Anim. 51,524-37. http://doi: 10.1111/rda.12714. Epub 2016 Jun 5.

Uysal, O. \& Bucak, M.N. 2007. Effects of oxidized glutathione, bovine serum albumin, cysteine and lycopene on the quality of frozen-thawed ram semen. Acta Veterinaria Brno. 76, 383-390. https://doi: 10.2754/avb200776030383.

Xia. S, Tan, C., Zhang, Y., Abbas, S., Feng, B., Zhang, X. \& Qin, F., 2015. Modulating effect of lipid bilayer-carotenoid interactions on the property of liposome encapsulation. Colloid Surfaces B. 128, 172-180. https://doi: 10.1016/j.colsurfb.2015.02.004.

Yániz, J.L., Palacín, I., Vicente-Fiel, S., Sánchez-Nadal, J.A. \& Santolaria, P. 2015. Sperm population structure in high and low field fertility rams. Anim. Reprod. Sci. 156, 128-134. https://doi: 10.1016/j.anireprosci.2015.03.012.

Yeste, M., 2016. Sperm cryopreservation update: Cryodamage, markers, and factors affecting the sperm freezability in pigs. Theriogenology 85: 47-64. http:// DOI:10.1016/j.theriogenology.2015.09.047.

Zheng, Z., Yin, Y., Lu, R. \& Jiang, Z., 2019. Lycopene ameliorated oxidative stress and inflammation in Type 2 diabetic rats. J Food Sci. 84,1194-1200. http://doi: 10.1111/1750-3841.14505.

Zini, A., Gabriel, M.S. \& Libman, J., 2010. Lycopene supplementation in vitro can protect human sperm deoxyribonucleic acid from oxidative damage. Fertil. Steril. 94, 1033-1036. https://doi: 10.1016/j.fertnstert.2009.04.004. 